\title{
Oral vinorelbine versus intravenous vinorelbine, in combination with epirubicin as first-line chemotherapy in Chinese patients with metastatic breast cancer
}

\author{
Liang Huang ${ }^{1,15} \cdot$ Xiaojia Wang $^{2} \cdot$ Liheng Zhou $^{3} \cdot{\text { Lijun } \mathrm{Di}^{4} \cdot \text { Hongyu Zheng }^{5} \cdot \text { Zefei Jiang }}^{6} \cdot$ Yongsheng Wang $^{7}$. \\ Xiangqun Song ${ }^{8}$. Jifeng Feng ${ }^{9}$. Shiying $\mathrm{Yu}^{10}$. Yunpeng Liu ${ }^{11}$. Hong Zheng ${ }^{12} \cdot$ Kunwei Shen $^{13} \cdot$ Zhongsheng Tong $^{14}$. \\ Zhimin Shao ${ }^{1,15}$
}

Received: 11 August 2019 / Accepted: 22 November 2019/ Published online: 14 December 2019

(c) The Author(s) 2019

\begin{abstract}
Oral VRL offers easier administration, better quality of life, and cost saving. This study aimed to evaluate the treatment efficacy in terms of tumor response of the two formulations of vinorelbine (VRL, oral and IV) in combination with epirubicin (EPI); and the effect of EPI co-administration on VRL pharmacokinetics (PK) in Chinese patients with metastatic breast cancer (MBC) using a phase 2, open label, randomized trial. Patients were aged 18-70 years, had histologically confirmed MBC, Karnofsky Performance Status $\geq 70 \%$, and life expectancy $\geq 12$ weeks. The treatment consisted of 6 cycles of 3 weeks each. VRL dose was: (Oral-VRL) $60 \mathrm{mg} / \mathrm{m}^{2}$ for cycle $1,80 \mathrm{mg} / \mathrm{m}^{2}$ for cycles $2-6$, and (IV-VRL) $25 \mathrm{mg} / \mathrm{m}^{2}$ for cycle 1 and $30 \mathrm{mg} / \mathrm{m}^{2}$ for cycles $2-6$. EPI dose of $75 \mathrm{mg} / \mathrm{m}^{2}$ was given on day 1 in both arms for all cycles. 133 patients were enrolled: 66 in Oral-VRL and 67 in IV-VRL arms. The median age for Oral-VRL and IV-VRL arms was 48.4 and 50.0 years, respectively. Objective response rates were 50.0\% (95\% CI 37.4-62.6\%) for Oral-VRL and 53.7\% (95\% CI 41.1-66.0\%) for IV-VRL. Both treatment arms met the efficacy objective target of at least 31 responses, demonstrating efficacy as first-line treatment for MBC. Similar blood PK profiles, exposures, and VRL clearance were observed between VRL + EPI vs VRL-only modalities for both arms. Oral VRL is comparable to IV VRL and an effective first-line treatment for Chinese patients with MBC. The activity of VRL + EPI combination is unaltered when VRL is given orally at recommended doses.
\end{abstract}

Keywords Metastatic breast cancer $\cdot$ Oral vinorelbine $\cdot$ Intravenous vinorelbine $\cdot$ Epirubicin $\cdot$ Chinese patients

$\begin{array}{ll}\text { Abbreviations } \\ \text { CI } & 95 \% \text { confidence intervals } \\ \text { CPMP } & \text { Committee for proprietary medicinal products } \\ \text { DI } & \text { Dose intensity } \\ \text { DVRL } & \text { 4- } O \text {-deacetylvinorelbine } \\ \text { EPI } & \text { Epirubicin } \\ \text { ICH } & \text { International conference on harmonization } \\ \text { ITT } & \text { Intent-to-treat } \\ \text { IV } & \text { Intravenous } \\ \text { LLOQ } & \text { Lower limit of quantification } \\ \text { LC } & \text { Liquid chromatography } \\ \text { LVEF } & \text { Left ventricular ejection fraction } \\ \text { MBC } & \text { Metastatic breast cancer }\end{array}$

Liang Huang and Xiaojia Wang are co-first authors.

Zhimin Shao

zhimingshao@outlook.com

Extended author information available on the last page of the article

$\begin{array}{ll}\text { MS } & \text { Mass spectrometry } \\ \text { MUGA } & \text { Multigated acquisition } \\ \text { NCI-CTC } & \begin{array}{l}\text { National cancer institute common toxicity } \\ \text { criteria }\end{array} \\ \text { ITT } & \text { Intent-to-treat } \\ \text { ORR } & \text { Objective response rate } \\ \text { PK } & \text { Pharmacokinetics } \\ \text { RDI } & \text { Relative dose intensity } \\ \text { RECIST } & \text { Response evaluation criteria in solid tumors } \\ \text { VRL } & \text { Vinorelbine }\end{array}$

\section{Introduction}

In China, breast cancer is the most common cancer in women, especially among those aged between 30 and 59 years and in urban areas, which had twice the incidence rate compared with rural areas [1, 2]. An estimated 1.6 million people in the country were diagnosed with breast cancer 
in 2014 and 1.2 million people succumbed to the disease annually [3]. This accounted for $12.2 \%$ of newly diagnosed breast cancers and $9.6 \%$ of deaths from breast cancer worldwide, and the incidence of breast cancer continues to rise by $1.1 \%$ annually [1].

Despite adjuvant chemotherapy, $25-30 \%$ of patients without, and $75-80 \%$ with histological axillary node involvement were expected to have recurrent and/or metastatic breast cancer (MBC) within 10 years and eventually succumb to the disease [4]. For the majority of patients with MBC, the disease is incurable, and the main treatment goal for the patient is palliation, with the aim of maintaining or improving the quality of life and possibly, duration of survival [5]. Nevertheless, incremental improvements in the duration of survival (estimated at $\sim 20$ months, range 13.2-29.5 months) have been achieved in the first-line treatment of advanced breast cancer, coincident with the use of new therapies and augmented with supportive care and improved diagnostic techniques [6].

Given its good therapeutic index, hormonal therapy is considered the first option for women with estrogen receptor or progesterone receptor positive disease with minor visceral involvement [7]. However, endocrine resistance typically occurs during the course of the disease and for most patients, cytotoxic chemotherapy is the mainstream treatment for MBC [8]. It offers disease control and palliative benefits, and improves survival and quality of life [9], especially in patients with hormonally insensitive disease or for whom hormonal therapies have failed.

Combination chemotherapy is the most commonly used palliative treatment for $\mathrm{MBC}$, and the main components of many standard regimens are taxanes and/or anthracyclines [10]. Chemotherapeutic agents with original mechanisms of action such as vinorelbine (VRL, Navelbine ${ }^{\circledR}$, Pierre Fabre Oncologie, Boulogne, France), capecitabine, and eribulin can provide further options for first-line treatment [8]. Vinorelbine, a 3rd generation vinca alkaloid, has shown a high therapeutic index compared to other vinca alkaloids. It is associated with lower neurotoxicity [11] and has been shown to be effective and well-tolerated in the treatment of MBC [12-14]. VRL has already been used in combination with anthracyclines in several clinical trials [15-17]. Clinical experience on the combination of intravenous (IV) VRL and epirubicin (EPI) for first-line treatment of metastatic breast cancer is rather extensive [16-18]. The oral formulation of vinorelbine is available as gelatine capsules. This drug formulation resolved earlier issues regarding drug stability and absorption of the active drug and its excipient $[11,19]$. This oral formulation has several advantages over the IV form: (1) it is easier to administer, (2) improves the quality of life in the palliative setting, and (3) lowers the cost of medical care as it avoids hospitalization and reduces administration cost $[20,21]$. Oral VRL is thus a useful alternative to the IV form and deserves further clinical investigation.

Studies on the use of oral VRL as a single-agent [22, 23] or in combination therapy with EPI [24-26] for the treatment of MBC in Asian patients were limited. The aim of this study was to evaluate the treatment efficacy in terms of tumor response of the two formulations of VRL (oral and IV), when used in combination with standard dose EPI, and the effect of EPI co-administration on VRL pharmacokinetics (PK) in Chinese patients with MBC.

\section{Materials and methods}

This phase 2, prospective, open label, multi-center, randomised trial enrolled Chinese patients with metastatic breast cancer between February 2008 and January 2010 at 12 sites in China. The protocol was approved by the Independent Ethics Committees at each site prior to the start of the study. The study was conducted in accordance with the ethical principles stated in the Declaration of Helsinki and subsequent amendments, and in compliance with Good Clinical Practice Guidelines (Committee for Proprietary Medicinal Products (CPMP)/International Conference on Harmonization (ICH/135/95). All patients signed informed consent prior to entry into the study.

\section{Patients}

Eligible patients were aged between 18 and 70 years, both inclusive. Those aged $>65$ years must not have $>3$ comorbidities which impacted cardiac, pulmonary, liver or renal functions. Patients must have (1) histologically confirmed adenocarcinoma of the breast and metastatic disease previously untreated by chemotherapy; (2) Karnofsky Performance Status (PS) $\geq 70 \%$; and (3) a life expectancy $\geq 12$ weeks. Prior adjuvant or neoadjuvant chemotherapy which contained an anthracycline and/or taxane (maximum cumulative dose: $360 \mathrm{mg} / \mathrm{m}^{2}$ for doxorubicin, $540 \mathrm{mg} / \mathrm{m}^{2}$ for EPI) and relapsing $>6$ months after the end of adjuvant chemotherapy, or prior hormonal therapy for metastatic breast cancer, was allowed. Patients may receive prior radiotherapy but not on sites used to assess response and where a minimum of 4 weeks' interval have elapsed. They had adequate bone marrow, hepatic, and renal functions, normal cardiac function, presence of at least one measurable indicator lesion (RECIST 1.0 criteria [27]) which was not previously irradiated, LVEF $\geq 50 \%$ as measured by MUGA scan or ultrasound, and absence of psychological, familial, sociological or geographical conditions potentially hampering compliance with the study protocol and follow-up schedule. 
Patients with poor disease prognosis such as inflammatory (T4d) disease, bilateral cancer, symptomatic lung lymphangitis; prior chemotherapy in the metastatic setting; concomitant hormone therapy for metastatic breast cancer, or previously treated with a vinca-alkaloid but relapsing $<6$ months after the chemotherapy were excluded. Other exclusion criteria were: active central nervous disorder, brain metastasis or leptomeningeal involvement; symptomatic neuropathy (sensory) $>$ grade 1 according to the National Cancer Institute Common Toxicity Criteria (NCI-CTC V2) [28]; concomitant/uncontrolled medical disorder (cardiac failure or myocardial infarction within the previous 3 months, uncontrolled hypertension or arrhythmia, unstable diabetes, uncontrolled hypercalcaemia, and clinically significant active infection requiring IV antibiotics within 2 weeks before the beginning of treatment).

\section{Study design}

Patients were randomized (1:1) into two arms: oral VRL + EPI (Oral-VRL arm, 60 patients) or IV VRL + EPI (IV-VRL arm, 60 patients). The study drug administration was initiated within 7 days after randomisation. The treatment consisted of 6 cycles of 3 weeks each. For each cycle, VRL was given on days 1 and 8 of the cycle. The administered dose of VRL for the Oral-VRL arm was $60 \mathrm{mg} / \mathrm{m}^{2}$ for cycle 1 and $80 \mathrm{mg} / \mathrm{m}^{2}$ for cycles 2-6 with a maximum dose of 120 and $160 \mathrm{mg}$, respectively. For the IV-VRL arm, the VRL dose was $25 \mathrm{mg} / \mathrm{m}^{2}$ for cycle 1 and $30 \mathrm{mg} / \mathrm{m}^{2}$ for cycles 2-6 with maximum doses of 50 and $60 \mathrm{mg}$, respectively. EPI was infused at the dose of $75 \mathrm{mg} / \mathrm{m}^{2}$ on day 1 in both arms for all cycles. Drug administration was cancelled in the event of disease progression, unacceptable toxicity or at patient's refusal. A patient was withdrawn if a cycle lasted $>5$ weeks (i.e. $>2$ weeks delay). Preventive antiemetic was given on day 1 according to the institutional protocols for each EPI/VRL administration and systematic antiemetic treatment with oral 5-HT3 antagonist, on day 8 prior to oral VRL administration.

\section{Study procedures}

Physical examination including vital signs, body weight and performance status was performed on day 1 of each cycle. Complete blood cell and platelet counts were performed on day 1 and day 8, and serum biochemistry on day 1 of each cycle. Each patient was followed for 30 days after the last drug administration and survival information was collected every 3 months.

Blood sampling for the VRL PK and its active metabolite 4-O-deacetylvinorelbine (DVRL) was performed for both arms in cycle 1 according to a six time-points limited sampling schedule after the co-administration of VRL and EPI on day 1 and administration of VRL alone on day 8. VRL and DVRL were assayed in whole blood by LC/MS-MS with a LLOQ of $0.25 \mathrm{ng} / \mathrm{mL}$.

\section{Study assessments}

The primary efficacy analysis was to assess the Objective Response Rate (ORR), i.e. patients with complete or partial remission, in both arms on the ITT population. Tumour assessment was performed according to the RECIST 1.0 method [27] at baseline and after every two cycles. After the completion of six cycles, the assessment was performed every 3 months until tumour progression was documented. Confirmation of an objective response was performed at least 4 weeks after documentation. A minimum of 31 responses was required to meet the efficacy objective. The secondary efficacy parameters analysed were: disease control rate, time to first response, duration of response, time to treatment failure, progression-free survival and overall survival. All adverse events were reported using the NCICTC system [28]. Maximum grade or severity was reported by cycle and by patient.

A subset of patients who completed their first cycle of treatment and had their blood sampled on days 1 and 8 of that cycle were evaluated for the effect of EPI co-administration on VRL PK. For each route of administration, the EPI drug-drug interaction analysis was evaluated by comparing Bayesian VRL PK parameters between day 1 (VRL + EPI) and day 8 (VRL alone).

\section{Statistical analyses}

The sample size was calculated according to the Fleming method [29] using reference response rates $(\mathrm{po}=0.40$, $\mathrm{pA}=0.60)$, error probabilities $(\alpha \leq 0.05, \beta \leq 0.10)$ and number of tests $(k=2)$. Assuming a 10\% non-evaluable rate, 132 patients were assigned for the trial. All descriptive statistics are presented in summary tables.

The analysis was performed on the intent-to-treat (ITT) population. All treated patients were included in the safety analysis unless the patient was lost to follow-up immediately after the start of the treatment. Continuous data are summarized with frequency and median [range]. Categorical data are presented in contingency tables with frequencies and percentages. The tumour response rate was assessed and 95\% CI were calculated following the exact method. Analyses of disease control rate, time to first response, duration of response, duration of disease control, progression-free survival and time to treatment failure was also performed, while overall survival was analysed with the Kaplan-Meier method. Statistical evaluation of drug bioavailability between days 1 and 8 was performed by a 2-way analysis of variance (5\% nominal $\alpha$ risk). Statistical analyses were 
carried out with SAS ${ }^{\circledR}$ version 8.2 for Windows ${ }^{\circledR}$ (SAS Institute Inc., 100 SAS Campus Drive Cary, NC 27513-2414, USA).

\section{Results}

\section{Patients}

Of the 133 patients enrolled, 66 patients were randomized to Oral-VRL and 67 to IV-VRL arms (Fig. 1). The number of patients who completed the treatment as per protocol in the Oral-VRL and IV-VRL arms was 37 and 41, respectively. As at the end of study (Feb 2011), 55 patients (Oral-VRL: 29, IV-VRL: 26) had discontinued treatment and the main reason was patient refusal or withdrawal of consent (OralVRL: 16, IV-VRL: 14).

The median age of patients in Oral-VRL and IV-VRL arms was $48.4(32.2-68.8)$ and 50.0 (31.3-65.7) years, respectively. Table 1 shows the patient demographics and disease characteristics. The two arms were similar in their age distribution profiles. The Oral-VRL arm had more patients at $70 \%$ Karnofsky PS: $7(10.6 \%)$ vs $1(1.5 \%)$ in IV-VRL arm, and less patients at 90\%: $44(66.7 \%)$ vs 51 (76.1\%) in IV-VRL arm. At diagnosis, most patients had ductal (Oral-VRL: 53.0\%, IV-VRL: 64.2\%) or invasive (OralVRL: $22.7 \%$, IV-VRL: $13.4 \%$ ) cancers. At study entry, there were 17 patients $(12.8 \%)$ at stage IV, with more patients in Oral-VRL arm (10 patients, 15.2\%) compared to IV-VRL arm (7 patients, $10.4 \%$ ). More patients in the Oral-VRL arm

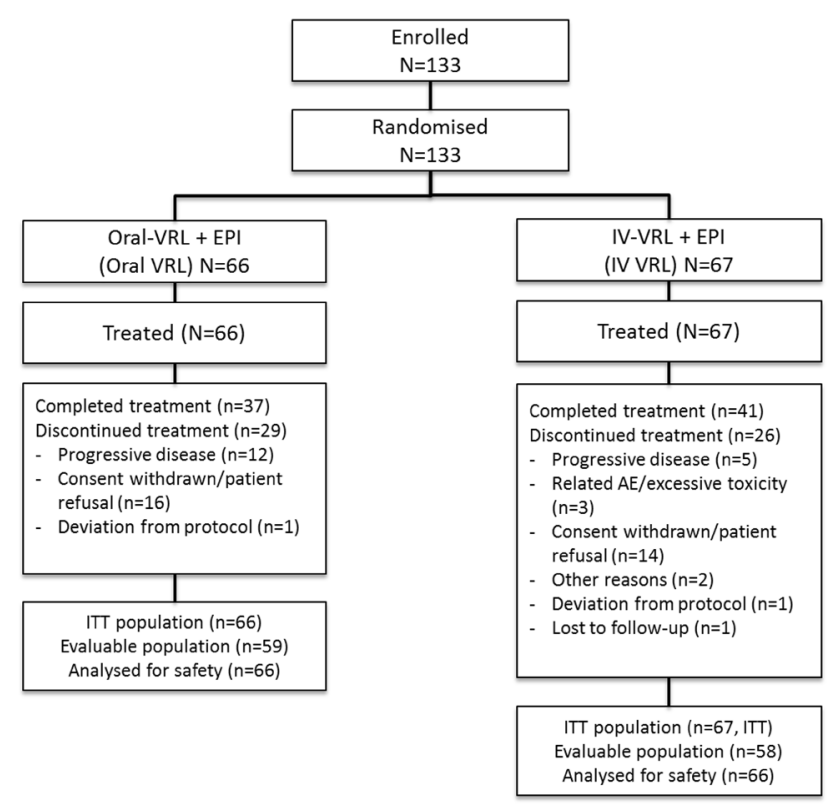

Fig. 1 Patient disposition. $A E$ adverse event, EPI epirubicin, ITT intent-to-treat, $I V$ intravenous, $V R L$ vinorelbine had $\geq 3$ organs involved ( 30 patients, $45.5 \%$ vs 20 patients, $29.9 \%$ patients in IV-VRL arm); and liver metastases (23 patients, $34.8 \%$ vs 18 patients, $26.9 \%$ in IV-VRL arm).

\section{Treatment exposure}

The median treatment duration for Oral-VRL and IV-VRL arms was 18.5 (3.0-23.9) and 18.7 (3.0-22.7) weeks, during which, patients in both arms had a median of $6(1-6)$ cycles of treatment. The median dose intensity (DI) for VRL was $40.0 \mathrm{mg} / \mathrm{m}^{2} /$ week in Oral-VRL arm and $15.4 \mathrm{mg} / \mathrm{m}^{2} /$ week for in IV-VRL arm. The relative dose intensity (RDI) was $80.0 \%$ and $80.3 \%$, respectively. For EPI, the median DI was $22.2 \mathrm{mg} / \mathrm{m}^{2} /$ week in Oral-VRL arm and $21.8 \mathrm{mg} / \mathrm{m}^{2} /$ week in IV-VRL arm with a RDI of $88.8 \%$ and $87.2 \%$ for both arms, respectively. The percentage of patients who had their VRL doses reduced were similar in both arms $(24.2 \%$ vs $22.4 \%$ ). However, more patients had their EPI doses reduced in IV-VRL arm (31.3\% vs $18.2 \%$ in Oral-VRL arm). The most common reason for a dose reduction was drug-related haematological toxicity: 14/17 (82.4\%) for Oral-VRL, 15/15 (100\%) for IV-VRL, and for EPI, 9/12 (75.0\%) and 20/21 (95.2\%) in Oral-VRL and IV-VRL arms, respectively.

From cycle 2 onwards, the percentage of cycles delayed at day 1 in Oral-VRL and IV-VRL arms was similar, i.e. 69/253 (27.3\%) and 74/267 (27.7\%), respectively. A higher percentage of patients on IV VRL had their day 8 drug administration delayed ( $18.1 \%$ vs $8.3 \%$ for Oral-VRL arm) or cancelled ( $11.2 \%$ vs $7.7 \%$ for Oral-VRL arm). The most frequent reason for a cancelled VRL administration was neutropenia, accounting for $33(89.2 \%)$ and $15(62.5 \%)$ of cancellations in IV VRL and Oral-VRL arms, respectively.

Of the 133 patients, $130(97.7 \%)$ advanced to cycle 2, and $71(53.4 \%)$ patients received the escalated VRL doses as planned: $41(62.1 \%)$ and $30(44.8 \%)$ in Oral-VRL and IVVRL arms, respectively. The other 59 patients received the same doses as in cycle 1: 24 (36.4\%) and 35 (52.2\%) patients in Oral-VRL arm and IV-VRL arms, respectively. Neutropaenia was the most common reason for non-escalation of doses: 15/24 (62.5\%) and 28/35 (80.0\%) in Oral-VRL and IV-VRL arms, respectively.

\section{Treatment efficacy}

For the ITT population, both arms achieved similar results for the primary efficacy endpoint, ORR, i.e. $50.0 \%$ and $53.7 \%$ for Oral-VRL arm and IV-VRL arms, respectively (Table 2). Both arms met the treatment efficacy objective target of a minimum of 31 responses. In Oral-VRL arm, 86.4\% (CI 75.7-93.6) of patients had the disease under control and similarly, 88.0\% (CI 77.8-94.7) in IV-VRL $\mathrm{arm}$. The median times to first response and to treatment failure in both arms were similar. At the end of the study, 
Table 1 Patient demographics and disease characteristics (ITT population)

\begin{tabular}{|c|c|c|c|c|c|c|}
\hline & \multicolumn{2}{|c|}{ Oral-VRL arm } & \multicolumn{2}{|c|}{ IV-VRL arm } & \multicolumn{2}{|l|}{ All } \\
\hline & $N=66$ & 100 & $N=67$ & 100 & $N=133$ & 100 \\
\hline & $n$ & $\%$ & $n$ & $\%$ & $n$ & $\%$ \\
\hline \multicolumn{7}{|l|}{ Age distribution, years } \\
\hline$<35$ & 2 & 3.0 & 4 & 6.0 & 6 & 4.5 \\
\hline 35 to $<50$ & 34 & 51.5 & 30 & 44.8 & 64 & 48.1 \\
\hline 50 to $<65$ & 29 & 43.9 & 32 & 47.8 & 61 & 45.9 \\
\hline$\geq 65$ & 1 & 1.5 & 1 & 1.5 & 2 & 1.5 \\
\hline \multicolumn{7}{|l|}{ Karnofsky PS } \\
\hline 70 & 7 & 10.6 & 1 & 1.5 & 8 & 6.0 \\
\hline 80 & 8 & 12.1 & 9 & 13.4 & 17 & 12.8 \\
\hline 90 & 44 & 66.7 & 51 & 76.1 & 95 & 71.4 \\
\hline 100 & 7 & 10.6 & 6 & 9.0 & 13 & 9.8 \\
\hline \multicolumn{7}{|l|}{ At diagnosis } \\
\hline \multicolumn{7}{|l|}{ Histology } \\
\hline Ductal, NOS & 35 & 53.0 & 43 & 64.2 & 78 & 58.6 \\
\hline Invasive, NOS & 15 & 22.7 & 9 & 13.4 & 24 & 18.0 \\
\hline Intraductal & 4 & 6.1 & 1 & 1.5 & 5 & 3.8 \\
\hline $\begin{array}{l}\text { Invasive with pre- } \\
\text { dominant intraductal } \\
\text { component }\end{array}$ & 4 & 6.1 & 4 & 6.0 & 8 & 6.0 \\
\hline Cancer, NOS & 3 & 4.5 & 3 & 4.5 & 6 & 4.5 \\
\hline Invasive & 2 & 3.0 & 2 & 3.0 & 4 & 3.0 \\
\hline $\begin{array}{l}\text { Medullary with lympho- } \\
\text { cytic infiltrate }\end{array}$ & 1 & 1.5 & - & - & 1 & 0.8 \\
\hline Lobular & - & - & 2 & 3.0 & 2 & 1.5 \\
\hline Mucinous & - & - & 2 & 3.0 & 2 & 1.5 \\
\hline Unknown & 2 & 3.0 & 1 & 1.5 & 3 & 2.3 \\
\hline \multicolumn{7}{|c|}{ Hormonal receptor status (Oestrogen/Proesterone) } \\
\hline Negative/negative & 17 & 25.8 & 21 & 31.3 & 38 & 28.6 \\
\hline Negative/positive & 5 & 7.6 & 4 & 6.0 & 9 & 6.8 \\
\hline Positive/negative & 9 & 13.6 & 10 & 14.9 & 19 & 14.3 \\
\hline Positive/positive & 26 & 39.4 & 26 & 38.8 & 52 & 39.1 \\
\hline Unknown/negative & 1 & 1.5 & 1 & 1.5 & 2 & 1.5 \\
\hline Unknown/unknown & 8 & 12.1 & 5 & 7.5 & 13 & 9.8 \\
\hline \multicolumn{7}{|l|}{ At study entry } \\
\hline \multicolumn{7}{|l|}{ Stage } \\
\hline Relapse & 56 & 84.8 & 60 & 89.7 & 116 & 87.2 \\
\hline Stage IV & 10 & 15.2 & 7 & 10.4 & 7 & 12.8 \\
\hline \multicolumn{7}{|l|}{ Number of organs involved } \\
\hline 1 organ & 16 & 24.2 & 23 & 34.3 & 39 & 29.3 \\
\hline 2 organs & 20 & 30.3 & 24 & 35.8 & 44 & 33.1 \\
\hline 3 or more organs & 30 & 45.5 & 20 & 29.9 & 50 & 37.1 \\
\hline
\end{tabular}

EPI epirubicin, ITT intent-to-treat, NOS not otherwise specified, $P S$ performance status, VRL vinorelbine the percentages of patients in the Oral-VRL and IV-VRL arms who had died or relapsed were $34.8 \%(23 / 66)$ and $32.8 \%$ (22/67), respectively. The median follow-up times for both arms were 7.6 and 8.2 months, respectively. Six patients in each arm deceased during the follow-up period. The progression-free survival and overall survival were not computed as there were insufficient patient data-points. 
Table 2 Efficacy Endpoints (ITT population)

\begin{tabular}{lll}
\hline & Oral-VRL arm $(N=66)$ & IV-VRL arm $(N=67)$ \\
\hline $\begin{array}{l}\text { Number of patients } \\
\text { Evaluable population }^{\mathrm{a}}, n(\%)\end{array}$ & $60(90.9)$ & $60(89.6)$ \\
Disease under control $^{\mathrm{b}}, n(\%)$ & $57(86.4)$ & $59(88.0)$ \\
Partial or complete remission, $n(\%)$ & $33(50.0)$ & $36(53.7)$ \\
$\quad$ Stable disease, $n(\%)$ & $24(36.4)$ & $23(34.3)$ \\
Progressive disease, $n(\%)$ & $3(4.5)$ & $1(1.5)$ \\
Not evaluable, $n(\%)$ & $6(9.1)$ & $7(10.4)$ \\
Primary endpoint & & $53.7(41.6-66.0)$ \\
Objective response rate (ORR) ${ }^{\mathrm{c}}, \%,(95 \% \mathrm{CI})$ & $50.0(37.4-62.6)$ & \\
Secondary endpoints: & & 60.0 \\
Tumor response rate ${ }^{\mathrm{d}}, \%$ & 55.0 & $88.0(77.8-94.7)$ \\
Disease under control, \% (95\% CI) & $86.4(75.7-93.6)$ & $1.8(1.3-4.9)$ \\
Median time to first response (95\% CI), months & $1.6(1.3-3.6)$ & $4.6(4.2-5.0)$ \\
Median time to treatment failure (95\% CI), months & $4.5(3.7-5.0)$ & \\
\hline
\end{tabular}

${ }^{a}$ Evaluable population: patients evaluable for tumour response were defined as follows: (a) patients who remained on study until the first evaluation and who were evaluated; (b) patients who progressed before the first evaluation were considered as early progression; (c) patients who died from malignant disease before the first evaluation were considered as early death; and (d) patients with baseline lesions assessed at least once after the first cycle, with the same method of measurement as baseline

${ }^{b}$ Disease under control: patients with complete or partial remission or stable disease

${ }^{c}$ Objective response rate: patients who had complete or partial remission of the disease

${ }^{\mathrm{d}}$ Tumour response rate: patients who had complete or partial remission of the disease in the evaluable population

\section{Safety and tolerability}

In Oral-VRL arm, 65 patients and 314 cycles were evaluable for the haematological toxicity during therapy administration, and 66 patients and 331 cycles in IV-VRL arm. About $80.0 \%$ and $92.4 \%$ of patients in Oral-VRL and IVVRL arms, respectively, had neutropaenia toxicity grades $3 / 4$, with a higher percentage of grade 4 in IV-VRL arm (83.3\% vs $58.5 \%$ in Oral-VRL arm). These adverse events occurred in $38.2 \%$ and $53.1 \%$ of cycles in Oral-VRL and IV-VRL arms, respectively. Table 3 shows the number of patients with grades $3 / 4$ toxicity adverse events. Febrile neutropaenia was reported in 9/65 (13.8\%) and 14/66 $(21.2 \%)$ of patients in Oral-VRL and IV-VRL arms and $9 / 314(2.8 \%)$ and $16 / 331$ (4.8\%) of cycles, respectively.

The most commonly reported non-haematological adverse events in Oral-VRL arm were nausea (75.8\%), vomiting $(69.7 \%)$ and anorexia $(51.5 \%)$; and similarly for IV-VRL arm, nausea (74.6\%), vomiting (59.7\%) and fatigue (56.7\%) (Table 3). No patients died within 30 days after the last drug administration. Six patients in Oral-VRL arm and five patients in IV-VRL arm subsequently died of progressive disease. One patient in IV-VRL arm died of pulmonary embolism.

\section{Pharmacokinetic analysis}

For Oral-VRL arm, 27/66 subjects (40.9\%) had blood sampled on day 1 and 26/66 (39.4\%) on day 8, and for IV-VRL arm, 20/67 (29.8\%) and 17/67 (25.4\%) on days 1 and 8, respectively. Figure 2 shows the individual VRL blood concentration profiles over time for VRL and its metabolite, DVRL for both arms. The day 1 profiles were superimposed over day 8 profiles. For both arms, the day 1 and 8 profiles overlapped and showed no differences in the PK between day 1 (VRL + EPI) and day 8 (VRL) (Figs. 3a, b). For IV-VRL, one patient was excluded as an outlier. The superimposed DVRL blood concentration profiles for days 1 and 8 in both arms were also similar (Figs. 3c, d). The metabolite exhibited low concentration levels $(<10 \mathrm{ng} /$ $\mathrm{mL}$ ). As in the VRL profile, the same outlier patient was excluded from the analysis.

The individual patient values for apparent clearance (Oral-VRL arm) and total body clearance (IV-VRL arm) at day 1 and day 8 are displayed in Fig. 3. In both arms, there was no obvious trend between the day 1 and day 8 patterns showing that the mean clearance and blood exposures were similar whether VRL was associated with EPI or not. 
Table 3 Adverse events of NCICTC toxicity grade $3 / 4$

\begin{tabular}{|c|c|c|c|c|c|c|}
\hline & \multicolumn{3}{|c|}{ Oral-VRL arm } & \multicolumn{3}{|c|}{ IV-VRL arm } \\
\hline & All & Grade 3 & Grade 4 & All & Grade 3 & Grade 4 \\
\hline Number of patients & $N=65$ & & & $N=66$ & & \\
\hline \multicolumn{7}{|c|}{ Hematological toxicities, $n(\%)$} \\
\hline Hemoglobin & $64(97.0)$ & $12(18.5)$ & - & $64(95.5)$ & $20(30.3)$ & $5(7.6)$ \\
\hline Leucocytes & $61(92.4)$ & $29(44.6)$ & $13(20.0)$ & $66(98.5)$ & $29(43.9)$ & $28(42.4)$ \\
\hline Neutrophils & $61(92.4)$ & $14(21.5)$ & $38(58.5)$ & $65(97.0)$ & $6(9.1)$ & $55(83.3)$ \\
\hline Platelets & $55(83.3)$ & $3(4.6)$ & $1(1.5)$ & $56(83.6)$ & $7(10.6)$ & - \\
\hline Number of patients & $N=66$ & & & $N=67$ & & \\
\hline \multicolumn{7}{|c|}{ Non-haematological toxicities, $n(\%)$} \\
\hline \multicolumn{7}{|c|}{ Gastrointestinal disorders } \\
\hline Nausea & $50(75.8)$ & $8(12.1)$ & - & $50(74.6)$ & $10(14.9)$ & - \\
\hline Vomiting & $46(69.7)$ & $14(21.2)$ & $1(1.5)$ & $40(59.7)$ & $9(13.4)$ & - \\
\hline Abdominal Pain & $6(9.1)$ & - & - & $8(11.9)$ & $2(3.0)$ & - \\
\hline Constipation & $9(13.6)$ & - & - & $12(17.9)$ & $1(1.5)$ & - \\
\hline Diarrhoea & $16(24.2)$ & - & - & $10(14.9)$ & - & $1(1.5)$ \\
\hline Stomatitis & $7(10.6)$ & $2(3.0)$ & - & $8(11.9)$ & $2(3.0)$ & - \\
\hline \multicolumn{7}{|c|}{ General disorders and administration site condition } \\
\hline Fatigue & $41(62.1)$ & $3(4.5)$ & - & $38(56.7)$ & $5(7.5)$ & $1(1.5)$ \\
\hline Influenza like illness & - & - & - & $4(6.0)$ & & \\
\hline Pyrexia & $8(12.1)$ & - & - & $16(23.9)$ & - & - \\
\hline $\begin{array}{l}\text { Metabolism and nutrition } \\
\text { disorders-anorexia }\end{array}$ & $34(51.5)$ & $4(6.1)$ & - & $28(41.8)$ & $5(7.5)$ & $1(1.5)$ \\
\hline \multicolumn{7}{|c|}{ Respiratory, thoracic an mediastinal disorders } \\
\hline Cough & $5(7.6)$ & - & - & $7(10.4)$ & - & - \\
\hline Interstitial lung disease & - & - & - & $4(6.0)$ & - & - \\
\hline $\begin{array}{l}\text { Skin and subcutaneous } \\
\text { tissue disorders-alo- } \\
\text { pecia }\end{array}$ & $21(31.8)$ & - & - & $25(37.3)$ & - & - \\
\hline \multicolumn{7}{|l|}{ Other investigations } \\
\hline Weight decreased & $16(24.2)$ & - & - & $15(22.4)$ & $1(1.5)$ & - \\
\hline
\end{tabular}

NCI-CTC National cancer institute-common toxicity criteria

\section{Discussion}

This phase II study compared the oral and IV formulations of VRL in combination with EPI for the treatment of Chinese patients with MBC. Both therapies achieved similar ORRs: $50.0 \%$ (95\% CI 37.4-62.6\%) for Oral-VRL arm and 53.7\% (95\% CI 41.1-66.0\%) for IV-VRL arm, and surpassed the treatment efficacy target of at least 31 responses. This demonstrated their efficacies as first-line treatments for MBC. The results were also consistent with treatment responses reported in a number of phase II/III studies of VRL as a first-line treatment (38-50\% [30-35]) and as a combination therapy with EPI (70.6\% [17], 64\% [24]) for MBC. Of note is that the efficacy result for the oral VRL in our study was achieved despite the presence of several negative prognostic factors in the Oral-VRL arm: it had more patients who were functionally impaired and had stage IV disease, liver metastases or $\geq 3$ organs involved, compared with the IV-VRL arm. The oral combination also delivered similar results for disease control rate, and median times to first response and to treatment failure compared with the IV combination. The median times to first response of 1.6-1.8 months and to treatment failure (4.5-4.6 months) were consistent with the 2 and 10 months, reported by Vici et al. [17] in a phase 2 trial investigating the activity of VRL + EPI as a first-line therapy for MBC.

VRL tolerability for both formulations was similar in our study. There were no differences in the haematological and non-haematological toxicities, an observation which was reported by Bourgeois et al. [36]. In our study, a dose escalation approach had been chosen to optimize the safety profile of the treatment. However, the percentage of patients with adverse events remained on the high side. Haematological toxicities were the most frequent adverse events in both arms, as to be expected from the mechanisms of action of VRL and EPI. However, the oral formulation reported 

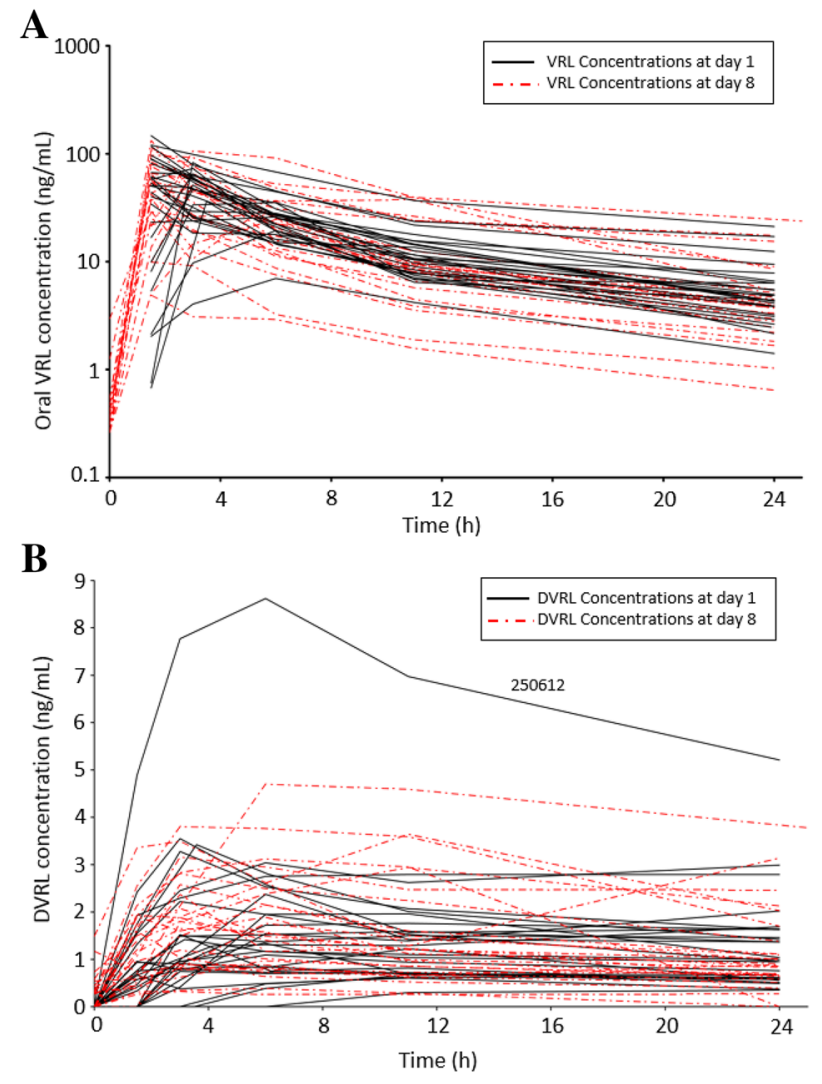

Fig. 2 Day 1 and 8 profiles of blood concentrations versus time profiles for $\mathbf{a}$ oral VRL and $\mathbf{b}$ its metabolite, DVRL and $\mathbf{c}$ IV VRL and $\mathbf{d}$ its metabolite, DVRL. Oral VRL dose was $60 \mathrm{mg} / \mathrm{m}^{2}$, IV VRL dose

less neutropaenia of grade $3 / 4(80.0 \%$ vs $92.4 \%)$ and less febrile neutropaenia (13.8\% vs $21.2 \%$ ) than for IV VRL. In contrast, leukopenia was reported as the dose-limiting toxicity in other VRL studies involving Asian patients [24, 25]. Non-haematological toxicity was similar between both arms. The most frequently reported gastrointestinal disorders, nausea, vomiting and constipation, occurred at low frequencies for grade $3 / 4$ events in both arms. Such side effects can be managed by standard antiemetic prophylaxis and dietary education.

A phase III trial performed by Ejlertsen, et al. [16] demonstrated that the addition of VRL to EPI induced a significant treatment advantage in terms of response rate and progression-free survival. Our study had a short follow-up period of 8 months which did not provide sufficient time to observe the complete progression-free rate and overall survival. Yan, et al. [25], however, observed a 5-year survival rate of $87.9 \%$ in a study of 61 Chinese patients with grade II/III breast cancer treated with IV VRL+EPI. EPI was well tolerated in our patients, without signs of chronic heart failure or LVEF observed in other studies on anthracycline-based chemotherapy $[37,38]$. This combination, oral VRL + EPI, for the first-line treatment of the metastatic
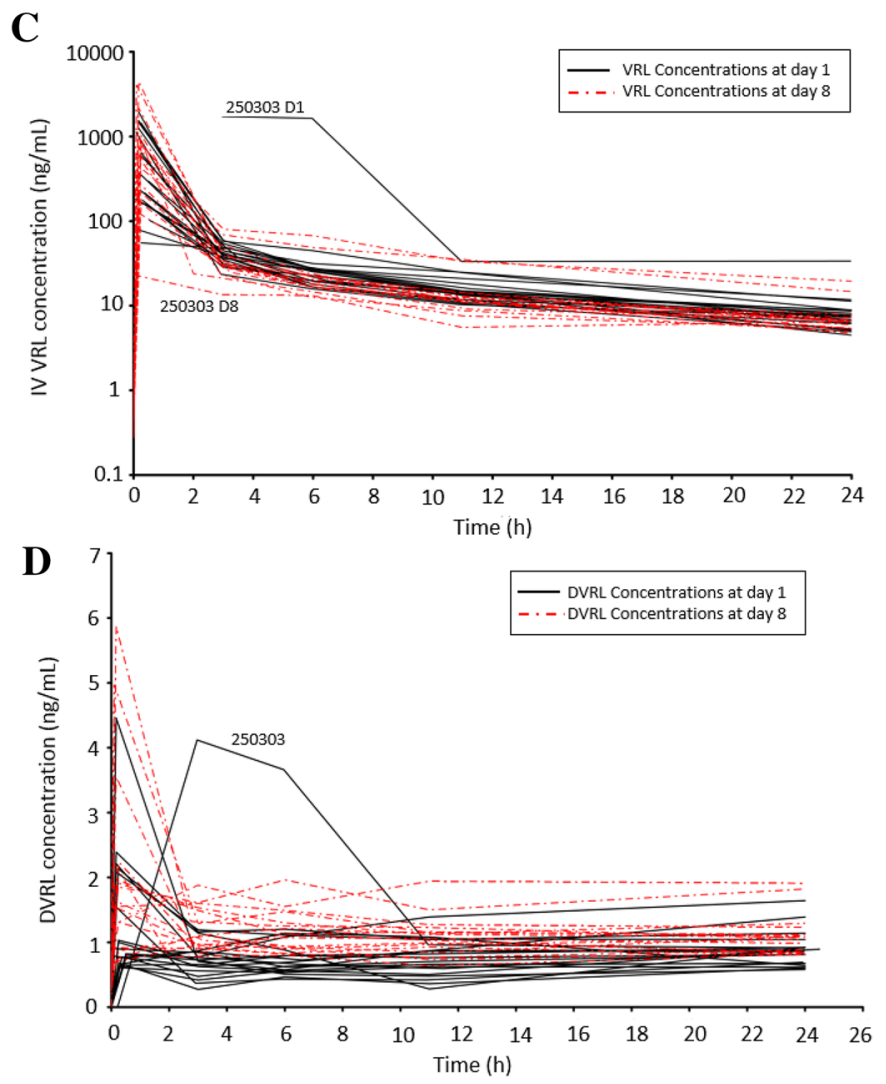

was $25 \mathrm{mg} / \mathrm{m}^{2}$. DVRL 4-O-deacetylvinorelbine, $I V$ intravenous, $V R L$ vinorelbine

disease is a useful alternative for those patients previously exposed to adjuvant anthracyclines. Our study also showed that the EPI in the combination therapy has limited effect on VRL PK, as suggested by the similar blood PK profiles, mean blood exposures and mean blood clearance of VRL between the two modalities of treatment (VRL+EPI vs VRL only) for both arms.

For patients with metastatic breast cancer, the oral VRL offers the advantages of an oral treatment, i.e. easier administration and better quality of life from greater convenience and comfort, without sacrificing efficacy and safety [21]. The simpler drug administration can alleviate oncology staff shortages, especially nurses and pharmacists, and provide savings in the cost of medical care. Moreover, oral chemotherapy can help to reduce the anxiety in patients who are afraid of injections $[39,40]$ and it can be a more appropriate route of administration when venous access is problematic. Many patients prefer oral chemotherapy because it improves their quality of life which is an important goal in a palliative setting $[15,20,41]$. The availability of an effective oral chemotherapy is also advantageous for patients living in remote areas or away from oncology centers and clinics. However, the preference of an oral chemotherapy is 


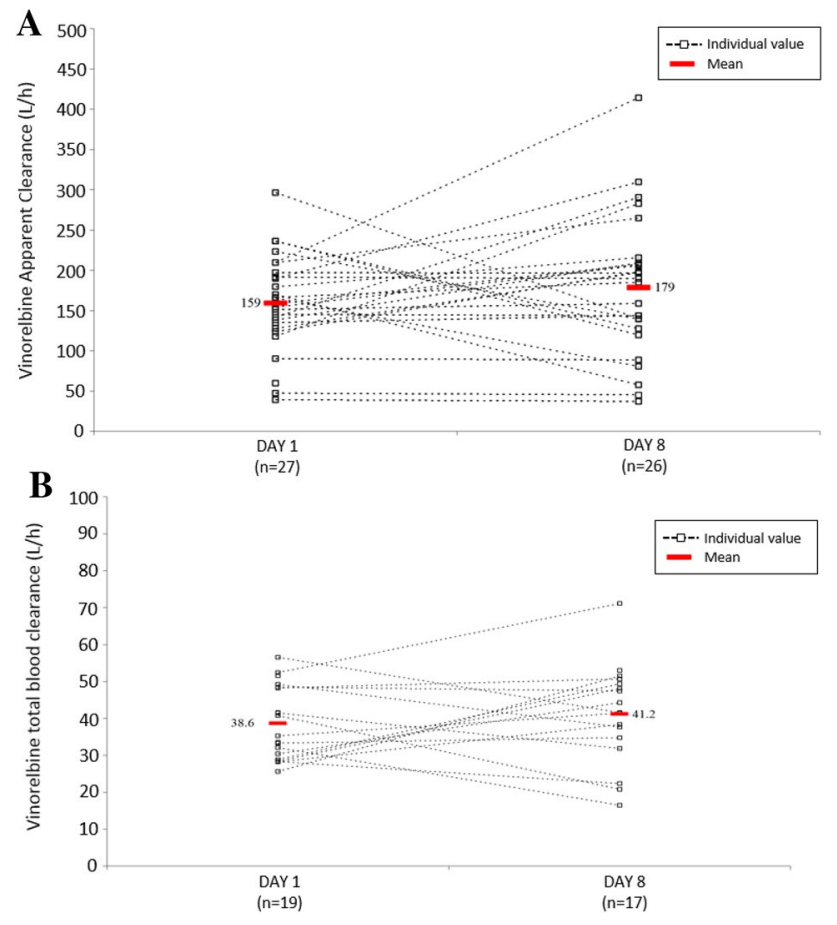

Fig. 3 Individual patient profiles for day 1 (VRL+EPI) and day 8 (VRL alone) for a apparent clearance, oral VRL and $\mathbf{b}$ total body clearance, IV VRL. Oral VRL dose was $60 \mathrm{mg} / \mathrm{m}^{2}$, IV VRL dose was $25 \mathrm{mg} / \mathrm{m}^{2}$. $E P I$ epirubicin, $I V$ intravenous, $V R L$ vinorelbine

conditioned by its efficacy that must be equivalent to the IV formulation in terms of treatment and toxicity: this has been demonstrated for VRL in our study.

\section{Conclusion}

Oral VRL in combination with EPI is an effective firstline treatment for Chinese patients with metastatic breast cancer. The efficacy of oral VRL is comparable to IV VRL with similar safety profiles and the activity of the VRL-EPI combination is unaltered when VRL is given orally at the recommended doses.

Acknowledgements Statistical analyses were performed by the Biometrics Department at IRPF-Centre de Développement Oncologie, Boulogne, France. Medical writing and editorial support was funded by Pierre Fabre Médicament and provided by Bao-Hui Lee and SenKwan Tay from Tech-Observer Asia Pacific Pte Ltd.

Funding This study was funded by Pierre Fabre Médicament.

\section{Compliance with ethical standards}

Conflict of interest The authors have no relevant relationships to disclose.
Ethical approval All procedures involving human participants were conducted in accordance with the ethical principles stated in the Declaration of Helsinki and subsequent amendments, and in compliance with Good Clinical Practice Guidelines (Committee for Proprietary Medicinal Products (CPMP)/International Conference on Harmonization (ICH/135/95). This article does not contain any studies with animals performed by any of the authors.

Informed consent Informed consent was obtained from all individual participants prior to study entry

Open Access This article is licensed under a Creative Commons Attribution 4.0 International License, which permits use, sharing, adaptation, distribution and reproduction in any medium or format, as long as you give appropriate credit to the original author(s) and the source, provide a link to the Creative Commons licence, and indicate if changes were made.The images or other third party material in this article are included in the article's Creative Commons licence, unless indicated otherwise in a credit line to the material. If material is not included in the article's Creative Commons licence and your intended use is not permitted by statutory regulation or exceeds the permitted use, you will need to obtain permission directly from the copyright holder.To view a copy of this licence, visit http://creativecommons.org/licenses/by/4.0/.

\section{References}

1. Chen W, Zheng R, Baade PD, Zhang S, Zeng H, Bray F, Jemal A, Yu XQ, He J (2016) Cancer statistics in China, 2015. CA Cancer J Clin 66(2):115-132. https://doi.org/10.3322/caac.21338

2. Shrubsole MJ, Jin F, Dai Q, Shu XO, Potter JD, Hebert JR, Gao YT, Zheng W (2001) Dietary folate intake and breast cancer risk: results from the Shanghai Breast Cancer Study. Cancer Res 61(19):7136-7141

3. Fan L, Strasser-Weippl K, Li JJ, St Louis J, Finkelstein DM, Yu KD, Chen WQ, Shao ZM, Goss PE (2014) Breast cancer in China. Lancet Oncol 15(7):e279-e289. https://doi.org/10.1016/S1470 -2045(13)70567-9

4. Harris JRL, Marc E, Morrow Monica, Osborne C Kent (2014) Diseases of the breast, 5th edn. Wolters Kluwer/Lippincott Williams \& Wilkins Health, Philadelphia

5. Cardoso F, Harbeck N, Fallowfield L, Kyriakides S, Senkus E (2012) Locally recurrent or metastatic breast cancer: ESMO Clinical Practice Guidelines for diagnosis, treatment and followup. Ann Oncol 23(Suppl 7):vii11-vii19. https://doi.org/10.1093/ annonc/mds 232

6. Ng W, Delaney GP, Jacob S, Barton MB (2010) Estimation of an optimal chemotherapy utilisation rate for breast cancer: setting an evidence-based benchmark for the best-quality cancer care. Eur J Cancer (Oxford, England: 1990) 46(4):703-712. https://doi. org/10.1016/j.ejca.2009.12.002

7. Ngan RKC (2018) Management of hormone-receptor positive human epidermal receptor 2 negative advanced or metastatic breast cancers. Ann Transl Med 6(14):284. https://doi. org/10.21037/atm.2018.06.11

8. Cardoso F, Colleoni M, Di Leo A, Francia G, Gennari A, Gligorov J, Llombart A (2016) Oral chemotherapy in advanced breast cancer: expert perspectives on its role in clinical practice. Cancer Treat Res Commun 6:S1-S10. https://doi.org/10.1016/S2213 -0896(16)06001-1

9. Partridge AH, Rumble RB, Carey LA, Come SE, Davidson NE, Di Leo A, Gralow J, Hortobagyi GN, Moy B, Yee D, Brundage SB, Danso MA, Wilcox M, Smith IE (2014) Chemotherapy 
and targeted therapy for women with human epidermal growth factor receptor 2-negative (or unknown) advanced breast cancer: american society of clinical oncology clinical practice guideline. J Clin Oncol 32(29):3307-3329. https://doi.org/10.1200/ jco.2014.56.7479

10. Andreopoulou E, Sparano JA (2013) Chemotherapy in patients with anthracycline- and taxane-pretreated metastatic breast cancer: an overview. Curr Breast Cancer Rep 5(1):42-50. https://doi. org/10.1007/s12609-012-0097-1

11. Galano G, Caputo M, Tecce MF, Capasso A (2011) Efficacy and tolerability of vinorelbine in the cancer therapy. Curr Drug Safety 6(3):185-193

12. Freyer G, Delozier T, Lichinister M, Gedouin D, Bougnoux P, His P, Imadalou K, Trillet-Lenoir V (2003) Phase II study of oral vinorelbine in first-line advanced breast cancer chemotherapy. J Clin Oncol 21(1):35-40. https://doi.org/10.1200/jco.2003.09.057

13. Steger GG, Dominguez A, Dobrovolskaya N, Giotta F, TubianaMathieu N, Pecherstorfer M, Ardizzoia A, Blasinska-Morawiec M, Espinosa E, Villanova G (2018) Single-agent oral vinorelbine as first-line chemotherapy for endocrine-pretreated breast cancer with bone metastases and no visceral involvement: NORBREAST-228 phase II study. Clin Breast Cancer 18(1):e41-e47. https://doi.org/10.1016/j.clbc.2017.05.012

14. Bruno S, Puerto VL, Mickiewicz E, Hegg R, Texeira LC, Gaitan L, Martinez L, Fernandez O, Otero J, Kesselring G et al (1995) Phase II trial of weekly i.v. vinorelbine as a single agent in firstline advanced breast cancer chemotherapy. The Latin-American experience. Am J Clin Oncol 18(5):392-396

15. Ardizzoia A, Colombo I, Giordano M, Aglione S, Isa L, Scanni A, Scognamiglio G, Bertolini A, Villa F, Gardani G (2007) Epirubicin-vinorelbine intravenous combination followed by oral vinorelbine as first-line treatment in metastatic breast cancer. Tumori 93(6):544-549

16. Ejlertsen B, Mouridsen HT, Langkjer ST, Andersen J, Sjostrom J, Kjaer M (2004) Phase III study of intravenous vinorelbine in combination with epirubicin versus epirubicin alone in patients with advanced breast cancer: a Scandinavian breast group trial (SBG9403). J Clin Oncol 22(12):2313-2320. https://doi. org/10.1200/jco.2004.11.503

17. Vici P, Colucci G, Gebbia V, Amodio A, Giotta F, Belli F, Conti F, Gebbia N, Pezzella G, Valerio MR, Brandi M, Pisconti S, Durini E, Giannarelli D, Lopez M (2002) First-line treatment with epirubicin and vinorelbine in metastatic breast cancer. J Clin Oncol 20(11):2689-2694. https://doi.org/10.1200/jco.2002.06.039

18. Nistico C, Garufi C, Barni S, Frontini L, Galla DA, Giannarelli D, Vaccaro A, D'Ottavio AM, Terzoli E (1999) Phase II study of epirubicin and vinorelbine with granulocyte colony-stimulating factor: a high-activity, dose-dense weekly regimen for advanced breast cancer. Ann Oncol 10(8):937-942

19. Brunello A, Roma A, Basso U, Jirillo A (2009) A review of vinorelbine in the treatment of advanced breast cancer. Clin Med Ther. https://doi.org/10.4137/cmt.s1153

20. Banna GL, Collova E, Gebbia V, Lipari H, Giuffrida P, Cavallaro S, Condorelli R, Buscarino C, Tralongo P, Ferrau F (2010) Anticancer oral therapy: emerging related issues. Cancer Treat Rev 36(8):595-605. https://doi.org/10.1016/j.ctrv.2010.04.005

21. Barni S, Freier B, Garau I, Mouysset JL, Sediva M, Zamagni C, Berdeaux G, de Almeida Agudo C (2016) Burden of advanced breast cancer for patients and caregivers in Europe: comparison of two treatment forms of vinorelbine, oral and intravenous. Curr Med Res Opin 32(11):1807-1812. https://doi.org/10.1080/03007 995.2016.1211518

22. Fan Y, Xu B, Yuan P, Wang J, Ma F, Li Q, Zhang P, Li Q, Cai R (2010) Prospective study of vinorelbine and capecitabine combination therapy in Chinese patients with metastatic breast cancer pretreated with anthracyclines and taxanes. Chemotherapy 56(4):340-347. https://doi.org/10.1159/000320186

23. Wang Y, Liu J, Jia W, Li S, Rao N, Su F, Liu Q, Yao H (2017) Comparison of the therapeutic efficacy of the early and the delayed use of vinorelbine-based regimens for patients with advanced breast cancer. Chemotherapy 62(1):71-79. https://doi. org/10.1159/000448472

24. Bang SM, Hong HS, Cha KH, Lee TH, Lee JA, Park YS, Cho EK, Shin DB, Lee JH (2000) Combination chemotherapy of vinorelbine and epirubicin (VE) in patients with advanced breast cancer. J Korean Cancer Assoc 32(2):244-252

25. Yan PW, Huang XE, Jiang Y, Tang JH, Xu HX, Xu X, Jin X (2010) Clinical comparison of safety and efficacy of vinorelbine/ epirubicin (NE) with fluorouracil/epirubicin/cyclophosphamide (FEC). Asian Pacific J Cancer Prevent 11(4):1115-1118

26. Huang O, Chen $\mathrm{C}$, Wu J, Chen S, Chen X, Liu G, Hu Z, Lu J, Wu J, Shao Z, Shen Z, Shen K (2009) Retrospective analysis of 119 Chinese noninflammatory locally advanced breast cancer cases treated with intravenous combination of vinorelbine and epirubicin as a neoadjuvant chemotherapy: a median follow-up of 63.4 months. BMC Cancer 9:375. https://doi. org/10.1186/1471-2407-9-375

27. Therasse P, Arbuck SG, Eisenhauer EA, Wanders J, Kaplan RS, Rubinstein L, Verweij J, Van Glabbeke M, van Oosterom AT, Christian MC, Gwyther SG (2000) New guidelines to evaluate the response to treatment in solid tumors. European organization for research and treatment of cancer, National Cancer Institute of the United States, National Cancer Institute of Canada. J Natl Cancer Inst 92(3):205-216

28. Division of Cancer Treatment \& Diagnosis (1998) Common toxicity criteria: version 2.0. National Cancer Institute, NIH. https:// ctep.cancer.gov/protocolDevelopment/electronic_applications/ctc. htm\#ctc_archive. Accessed 14 Nov 2018

29. Fleming TR (1982) One-sample multiple testing procedure for phase II clinical trials. Biometrics 38(1):143-151

30. Fumoleau P, Delgado FM, Delozier T, Monnier A, Gil Delgado MA, Kerbrat P, Garcia-Giralt E, Keiling R, Namer M, Closon MT et al (1993) Phase II trial of weekly intravenous vinorelbine in first-line advanced breast cancer chemotherapy. J Clin Oncol 11(7):1245-1252. https://doi.org/10.1200/jco.1993.11.7.1245

31. Garcia-Conde J, Lluch A, Martin M, Casado A, Gervasio H, De Oliveira C, De Pablo JL, Gorostiaga J, Giron GC, Cervantes A et al (1994) Phase II trial of weekly IV vinorelbine in first-line advanced breast cancer chemotherapy. Ann Oncol 5(9):854-857

32. Romero A, Rabinovich MG, Vallejo CT, Perez JE, Rodriguez R, Cuevas MA, Machiavelli M, Lacava JA, Langhi M, Romero Acuna L et al (1994) Vinorelbine as first-line chemotherapy for metastatic breast carcinoma. J Clin Oncol 12(2):336-341. https ://doi.org/10.1200/jco.1994.12.2.336

33. Terenziani M, Demicheli R, Brambilla C, Ferrari L, Moliterni A, Zambetti M, Caraceni A, Martini C, Bonadonna G (1996) Vinorelbine: an active, non cross-resistant drug in advanced breast cancer. Results from a phase II study. Breast Cancer Res Treat 39(3):285-291

34. Twelves CJ, Dobbs NA, Curnow A, Coleman RE, Stewart AL, Tyrrell CJ, Canney P, Rubens RD (1994) A phase II, multicentre, UK study of vinorelbine in advanced breast cancer. Br J Cancer 70(5):990-993

35. Weber BL, Vogel C, Jones S, Harvey H, Hutchins L, Bigley J, Hohneker J (1995) Intravenous vinorelbine as first-line and second-line therapy in advanced breast cancer. J Clin Oncol 13(11):2722-2730. https://doi.org/10.1200/JCO.1995.13.11.2722

36. Bourgeois H, Vermorken J, Dark G, Jones A, Fumoleau P, Stupp R, Tourani J, Brain E, Nguyen L, Lefresne F, Puozzo C (2007) Evaluation of oral versus intravenous dose of vinorelbine to achieve equivalent blood exposures in patients with solid 
tumours. Cancer Chemother Pharmacol 60(3):407-413. https:// doi.org/10.1007/s00280-007-0510-Z

37. Banke A, Fosbol EL, Moller JE, Gislason GH, Andersen M, Bernsdorf M, Jensen MB, Schou M, Ejlertsen B (2018) Longterm effect of epirubicin on incidence of heart failure in women with breast cancer: insight from a randomized clinical trial. Eur J Heart Fail 20(10):1447-1453. https://doi.org/10.1002/ejhf.1168

38. Schaadt B, Kelbaek H (1997) Age and left ventricular ejection fraction identify patients with advanced breast cancer at high risk for development of epirubicin-induced heart failure. J Nucl Cardiol 4(6):494-501

39. Damle B, Ravandi F, Kaul S, Sonnichsen D, Ferreira I, Brooks D, Stewart D, Alberts D, Pazdur R (2001) Effect of food on the oral bioavailability of UFT and leucovorin in cancer patients. Clin Cancer Res 7(3):517-523
40. Faithfull S, Deery P (2004) Implementation of capecitabine (Xeloda) into a cancer centre: UK experience. Eur J Oncol Nurs 8(Suppl 1):S54-S62. https://doi.org/10.1016/j.ejon.2004.06.009

41. Serin D, Verrill M, Jones A, Delozier T, Coleman R, Kreuser ED, Mross K, Longerey B, Brandely M (2005) Vinorelbine alternating oral and intravenous plus epirubicin in first-line therapy of metastatic breast cancer: results of a multicentre phase II study. Br J Cancer 92(11):1989-1996. https://doi.org/10.1038/sj.bjc.6602588

Publisher's Note Springer Nature remains neutral with regard to jurisdictional claims in published maps and institutional affiliations.

\section{Affiliations}

\section{Liang Huang ${ }^{1,15} \cdot$ Xiaojia Wang $^{2} \cdot$ Liheng Zhou $^{3} \cdot{\text { Lijun } \mathrm{Di}^{4} \cdot \text { Hongyu Zheng }^{5} \cdot \text { Zefei Jiang }}^{6} \cdot$ Yongsheng Wang $^{7}$. Xiangqun Song ${ }^{8}$. Jifeng Feng ${ }^{9} \cdot$ Shiying $\mathrm{Yu}^{10} \cdot$ Yunpeng Liu ${ }^{11} \cdot$ Hong Zheng ${ }^{12} \cdot$ Kunwei Shen $^{13} \cdot$ Zhongsheng Tong $^{14}$. Zhimin Shao ${ }^{1,15}$}

1 Department of Breast Surgery, Fudan University Shanghai Cancer Center/Cancer Institute, 399 Ling-Ling Road, Shanghai 200032, People's Republic of China

2 Zhejiang Cancer Hospital, No.1, East Banshan Road, Gongshu District, Hangzhou 310022 , People's Republic of China

3 Shanghai Jiatong University School of Medicine Renji Hospital, 145 Shandong Middle Rd, Huangpu Qu, Shanghai 200333, People's Republic of China

4 Beijing Cancer Hospital, 52 Fucheng Rd, Wu Ke Song, Beijing 100091, People's Republic of China

5 Fujian Provincial Cancer Hospital, 91 Fengban Maluding, Fuma Lu, Jin'an District, Fuzhou 350014, People's Republic of China

6307 Hospital of PLA, 8 East St, Fengtai Qu, Beijing 100160, People's Republic of China

7 Shangdong Cancer Hospital, Jinan 250117, People's Republic of China

8 Guangxi Medical University Affiliated Cancer Hospital, Fukang Rd, Qingxiu Qu, Nanning 530015, People's Republic of China
9 Jiangsu Cancer Hospital, Nanjing 210009, Jiangsu, People's Republic of China

10 Tongji Hospital, No.1095 Jie Fang Avenue, Hankou, Wuhan 430030, People's Republic of China

11 The First Hospital of China Medical University, Taiyuan Street Business Area, Heping, Shenyang 110003, People's Republic of China

12 West China Hospital of Sichuan University, No.37 Guoxue Alley, Wuhou District, Chengdu, Sichuan, People's Republic of China

13 Ruijin Hospital Shanghai Jiao Tong University School of Medicine, No. 197, Rui Jin Er Road, Shanghai 200025, People's Republic of China

14 Tianjin Medical University Cancer Institute and Hospital, Binshui Rd, Hexi Qu, Tianjin 300011, People's Republic of China

15 Department of Oncology, Shanghai Medical College, Fudan University, 138 Yixueyuan Rd, Shanghai 200333, People's Republic of China 